\title{
4
}

\section{Delivering public policy programs to senior executives in government-the Australia and New Zealand School of Government 2002-18}

\author{
John Wanna
}

Leadership and executive development programs have a long trajectory in the Australian and New Zealand public sectors, but there is currently a growing concern that many of the skills and capacities of leadership and policy advice have been eroded and/or neglected (Tiernan 2011, 2015). In recent times, dedicated leadership development programs have become intrinsically important in enhancing individual and collective organisational capacities, often integrated within formal staff appraisal processes and performance review systems. The prevailing pedagogical philosophies behind such programs have centred on developing organisational human resource capabilities and encouraging leadership potentialities in a team-based context aimed at problem-solving and performance results. This chapter examines the origin and development of the Australia and New Zealand School of Government (ANZSOG), which, for almost 20 years, has delivered executive developmental

\footnotetext{
1 The author wishes to thank Catherine Althaus, Trish Mercer, Val Barrett, Isi Unikowski and Robert McMahon for comments and suggestions on an earlier draft, and Peter Allen for his contribution to an earlier version of this chapter.
} 
programs to middle and senior executive public policy practitioners across both countries and to the wider geographic region. It also discusses many of the persistent dilemmas and challenges faced by those engaged in executive training more generally.

\section{The evolution of specialised executive education}

Australia and New Zealand have both established permanent-based civil services that enjoy formal statutory status while preserving their separation (and protection) from politics and minimising ministerial involvement in senior appointments. Public service organisations (departments and statutory authorities) are administratively interdependent with government, working professionally with Cabinet and its ministers, requiring staff to become politically savvy without being politically active. Over time and through experience, senior public servants have developed considerable administrative expertise (the 'craft'), advisory skills ('mastery') and effective relations with elected (and frequently changing) ministries. Even from colonial times, these public services have become career services, generally unified as a jurisdictional workforce, enshrining the principles of continuity, neutrality, anonymity and relying on largely internal notions of merit. The entrenchment of tenure for officials has largely established the current structure and cultures of public service. Typically, public servants learnt their vocation and were trained in the art of administration through constant on-the-job experiences, acquired competencies and some occasional training ('training for purpose').

Throughout most of the twentieth century, public services across Australasia were staffed by a combination of predominantly generalist administrators with some specialist professions or scientific grades. They were highly insular and not open to 'strangers' (with very little lateral recruitment or 'lateral entry' from outside), becoming increasingly bureaucratically industrial in their employment orientations (with strong public sector unions organised by administrative categories). For decades, governments and their central personnel management agencies (the public service boards in Australia or state services commissions in New Zealand) were preoccupied with improving the quality and reliability of administration, including economy and efficiency, routinisation and consistency of administrative practice, due diligence, compliance 
accountability and ethics (Public Service \& Merit Protection Commission [PSMPC] 2001). More recently, these perennial bureaucratic issues have tended to be overshadowed (but not totally displaced) by the imperatives of improved management, greater reliance on business techniques, performance and program effectiveness over results and outcomes, capacity-building, developing outward-oriented cultures of responsiveness and client-focused forms of service delivery, and consultative practices and public engagement. However, the turn towards new public management (NPM) from the 1980s onwards led to accusations that managerial imperatives had severely impacted on policy capabilities and 'hollowed out' state capacities.

Training and development for public servants was not a statutory requirement (and is not mentioned in the Australian Public Service Act 1999 and no longer in the New Zealand State Services Act 1988) but service-wide bodies and individual agencies maintained an enduring interest in 'training for purpose'. Most of the larger agencies tended to operate their own training activities (often contracting external providers for specific programs or workshops), while central agencies (public service boards or commissions) retained some overall service-wide responsibilities, including coordination, and ensuring agencies fulfil their training and executive development obligations. Accordingly, most training and development was fragmented and conducted at the individual agency level, with considerable 'in-service' delivery and customised on-the-job training. Taken together, these training regimes formed a matrix of selfadministered, 'job-focused' training, generally characterised by piecemeal internal provision, short-term foci, stop-start delivery and lack of credit (i.e. 'not-for-credit', meaning that the training did not count as an uppersecondary or tertiary qualification). These 'in-service' offerings, resourced primarily at the individual agency level, could be supplemented at the individual officer level by formal 'out-service' instruction 'for credit' (qualification-based programs delivered by business and secretarial colleges, night schools and further education colleges, dedicated training institutes and universities).

Historically, no Australian or New Zealand jurisdiction chose to invest in a single, monopoly provider to deliver training services across the entire public sector (although both armed forces did so with specialist training institutes). One of the main considerations may have been the recurrent direct costs likely to be involved, with agencies preferring to allocate smaller amounts from general staff budgets year by year. There has never 
been an equivalent in Australia or New Zealand to the central civil service colleges, such as the centrally funded Singapore Civil Service College or Taiwanese National Academy of the Civil Service with service-wide responsibilities for training and development. This is not to say that there have not been constant tensions between and debates over the merits of agency-specific 'competency training' and the 'holy grail' of devising centrally coordinated generic training regimes.

As the number of graduates entering the various services increased, demands for more externally provided training and education grew. Once graduates rose through the ranks, these more educated public servants stressed the importance of knowledge and intellectual and analytic abilities. By the 1980s, attention turned to middle management training and business and management training, often with graduates undertaking subsequent graduate diplomas and masters courses in professional areas, including business administration, law and accounting. Internal training tended then to focus on competency-based training, gap analysis for required skills and selective recruitment. A frequent structure for courses was based on three themes: technical skills, interpersonal skills and selfmanagement skills (Public Service Commission [PSC] 1992, pp. 37-8). A government mandated training guarantee program in the early $1990 \mathrm{~s}$ requiring agencies to spend 2 per cent of their budgets on training saw the proliferation of many private sector training organisations and providers of organised conferences on work-related topics under the banner of training. In addition, a number of 'senior executive services' (SES) had been created by the early 1990s across Australian jurisdictions, and specialist development programs were devised for this cohort, including a dedicated induction program called SEMP (Senior Executive Management Program). Executive development relied on a formal leadership capability framework to broaden capabilities and develop high performance leadership (by encouraging participants to develop executive capabilities to shape strategic thinking, cultivate productive working relations, communicate with influence, exemplify personal drive and integrity, and achieve results) (see Australian Public Service Commission [APSC] 2004). At the same time, a 'cooperative venture' between all the Australian jurisdictions and a consortia of universities provided middle management development instruction with formal university qualifications (graduate certificate) in the public sector management course (PSMPC 2001, p. 191). As the 
2000s progressed, many jurisdictions adopted forms of an integrated leadership framework' applying to their SES and other executive levels (see APSC 2004; APSC 2014).

Government departments and individual public servants energised the demand for formal qualifications (e.g. tertiary degrees, advanced diplomas, graduate diplomas or masters by coursework) as endemic 'credentialism' manifested itself in the public service. By the 1990s, almost all new recruits now possessed graduate qualifications (or were close to graduating), and many were sponsored to undertake (relevant) higher level studies, especially vocationally oriented masters courses (e.g. public policy, policy studies, public management, administrative law, accounting or generic business studies). Universities and further education colleges expanded their vocational offerings and began to tap the part-time student and distance education markets. However, at the same time, traditional courses in the building blocks of public administration tended to decline as academic specialisations, replaced by more generic courses in business techniques, organisational design, human resource management, computing studies and information technology (Davis \& Wanna 1997). The number of Australian institutions offering master of business administration (MBA) courses increased from two in the 1970s to over 30 by the late 2000s, and in New Zealand from one in the 1970s to eight in 2019, and, for a while, these business-oriented higher degrees were remarkably popular with public servants and their departmental supervisors (despite their frequent lack of fit). Eventually, rivalling this development of generic business credentialism was the establishment of a number of dedicated public policy tertiary courses; some were offered at the undergraduate level but most were provided at the masters level to graduates (see Di Francesco 2015). Enrolments across tertiary institutions in Australia increased from 200,000 in 1985 to 600,000 by 2014 , forming a huge pool of educated jobseekers from which to recruit staff.

New Zealand tended to concentrate public management training at Victoria University of Wellington in the postgraduate public management courses in the School of Government, and through the policy-applied Institute for Policy Studies. The University of Auckland also developed a popular masters in public policy. Australia saw the growth of specialist professional institutions delivering executive education to public servants. Most noticeably, there arose dedicated training centres such as the Australian Administrative Staff College, a residential executive college established in 1954 that later became the Mount Eliza Business School (and then 
merged in 2004 with the Melbourne Business School of the University of Melbourne). There was also increased provision from leadership academies and from various professional bodies, such as the various public service commissions, the Australian Institute of Management, the Institute of Public Administration of Australia and New Zealand's Institute of Public Administration. These professional bodies tended to provide professionally oriented and vocational training, and also concentrated on some generic capabilities (e.g. public policy skills, business and management techniques, accounting and specialist law programs, and health and safety training). A host of private sector training and executive development providers also sprang up from the 1980s, often headed by former top executives from the public and private sectors.

\section{A unique Trans-Tasman experiment in developing senior executive capabilities}

In the early 2000s, a significant innovation occurred in the Australian and New Zealand context in the formation of a dedicated executive development institution jointly owned by government jurisdictions with member universities - the Australia and New Zealand School of Government (see Allen \& Wanna 2016). ANZSOG's stated purpose was to become:

A world-class centre providing cutting-edge research and tailored learning opportunities for future leaders of the public sector. ANZSOG's purpose is to encourage improved public sector leadership, decision-making, policy outcomes and performance for the benefit of the community. ANZSOG plays a crucial role in promoting public service as a vocational profession of great social value to the public interest. (ANZSOG n.d.)

To achieve these ambitious objectives ANZSOG concentrated on three core functions:

1. to provide executive education development including the Executive Fellows Program (EFP) for senior executives and the Executive Master of Public Administration (EMPA) degree for mid-career government officials

2. to produce a high-quality inductive 'teaching case' collection available for training and executive development (currently around 200 cases are available for use) 
3. to undertake an active research program investigating topics of immediate relevance to public sector managers in order 'to deepen knowledge and understanding of government and to disseminate that understanding throughout the community'. ${ }^{2}$

The creation of ANZSOG was actually brought about because other specialist or tertiary institutions were not providing these functions, or not providing them to the satisfaction of key public sector leaders. There was an ambition in both countries to improve public sector capabilities and performance in delivery (Fels 2003). There was also a sense of a perceived policy capability gap afflicting both countries as a direct result of nearly 20 years of NPM (Boston \& Eichbaum 2014; Podger 2003; Tiernan 2015). With regard to the existing university programs, ANZSOG was the response to the perception of various Australian governments that there was a 'market failure' in the provision and quality of training and development programs available for public sector executives, especially focused on public leadership and management. Governments, therefore, took the initiative (and made the necessary investments) to create, with the collaboration and support of leading Australian and New Zealand universities, their own multi-jurisdictional school of government to which they could send their mid-senior executives identified as likely future leaders.

\section{The establishment of the school in 2002}

The establishment of ANZSOG in 2002 reflected a proactive recognition that the task of designing, delivering and maintaining the quality of professional development for future public sector leaders was challenging governments and specialist educational providers across the world. Existing approaches ranged from reliance on dedicated governmentowned institutions (such as the Singapore Civil Service College and the French Ecole Nationale d'Administration) to specialist institutes attached to leading universities. In this latter category the United States, for example, had a number of world-class providers such as Harvard's John F Kennedy School of Government, the Brookings Institute, the

2 These objectives have changed only slightly since 2002-03. The most recent statement of the school's objectives state that its purpose is 'dedicated to creating value for citizens by providing worldclass education for public sector leaders, conducting research and facilitating informed discussion on issues that matter for public sector performance, and promoting and supporting innovation in the public sector' (ANZSOG 2013). Only the last phrase is an augmentation on earlier statements. 
Woodrow Wilson School of Public and International Affairs (Princeton) and the Goldman School of Public Policy at California's Berkeley University. Recent United Kingdom experience has witnessed the demise of the government-owned National School of Government in 2012 (Civil Service College and Cabinet Office), although new initiatives have emerged as replacements, such as the Oxford University Blavatnik School of Government as well as continuing roles for established providers such as the London School of Economics and Warwick University. Against this background, public sector leaders in Australia and New Zealand determined to pursue a distinctively different approach to executive development, one that attempted to harmonise and build on the respective capacities of governments and universities across the two nations.

While many universities had graduate programs aimed at public officials, they were all constrained by limited demand; comparatively small, regionally focused academies; and limited, highly conditional, support from public service leaders. There was also a growing concern that the executive development of public executives was becoming a case of 'market failure': a dissipated and fragmented pattern of tertiary education institutions not investing in the required intellectual perspectives and teaching expertise to produce the required specialist courses and training opportunities that governments needed and requested. Accordingly, a new consolidated model was needed to provide customised high-quality public sector executive education to meet the governments' specific needs.

The decision to establish a bi-national school of government occurred almost by accident. A small group of senior officials led by the head of the Victorian Premier's Department, Terry Moran (also former CEO of the Australian National Training Authority), began discussing the possibility of a dedicated teaching institution across several Australian states. New Zealand officials heard of this development and expressed a keen interest to join. In many ways, this unplanned enhancement crystallised the opportunity and pedagogic benefits of collaborative action across government and universities. However, this necessitated the Commonwealth coming in, which, under the Howard government, it was at first disinclined to do, but later it agreed to join and augment the funding. ${ }^{3}$

3 In fact, the final agreement to form ANZSOG was reached at a Council of Australian Governments dinner in 2002 when a group of heads of first ministers' departments convinced the Commonwealth to join and send officers to the programs. John Howard's head of the Department of Prime Minister and Cabinet, Max Moore-Wilton, gave an undertaking to join, provided the state heads stopped badgering him about it. 
By mid-2002, five 'foundation members' had been identified with commitments for three years to fund the agreed intake for two initial ANZSOG executive development programs. One was the EMPA aimed at executive level officers with between five and 10 years public sector experience, and largely taught in block intensive mode. The second was a three-week intensive EFP targeted at SES officers. In November 2002, an agreement was signed by the founding governments and with the associated university partners. ${ }^{4}$ The member governments were themselves responsible for nominating participants for ANZSOG programs in addition to fully paying for them, ideally selecting those they believed to have considerable potential and leadership capabilities. Significantly, all participants to the main educational programs were government sponsored, meaning individual public servants could not voluntarily enrol in ANZSOG or personally pay tuition fees, nor could private sector managers elect to enrol.

Enrolment of the initial 130 public sector managers in the inaugural EMPA was completed and the first week-long course ('Delivering public value') was presented in May 2003, with the balance of the 10-course masters program delivered through 2003 and 2004. The inaugural delivery of the more senior EFP occurred across October and November 2003, with an enrolment of 80 senior public officials from across Australia and New Zealand, and a faculty drawn from Australian, New Zealand, United States and United Kingdom universities, and Australian and New Zealand public sector leaders. Gradually, the other jurisdictions (South Australia, Tasmania, Western Australia, the Northern Territory and the Australian Capital Territory) joined, bringing with them additional university partners. ANZSOG programs have expanded to include a program for public sector managers making the transition from operational to strategic leadership roles ('Towards Strategic Leadership' [TSL]), an extensive range of executive education short courses, programs aimed at building public sector capability in the Asia-Pacific region, a leadership development program for local government and an increasingly active

4 The five original jurisdictional members comprised the governments of the Commonwealth of Australia, New Zealand, Victoria, Queensland and New South Wales. The nine founding university members were The Australian National University, the University of Canberra, the University of Victoria, Monash University, the Melbourne Business School, Griffith University, the University of Queensland, the University of Sydney and the University of New South Wales. Subsequently, all other Australian governments (South Australia, Western Australia, Tasmania, the Northern Territory and the Australian Capital Territory, and seven additional universities agreed to join ANZSOG). 
research program (see ANZSOG 2013, 2016). By 2019, the total number of alumni across the school's three main programs (EMPA, EFP and TSL, but not including executive education short courses) was over 4,000.

An important feature distinguishing ANZSOG from other international public service training institutes, such as the former UK National School of Government, has been the role of, and investment in, research, which both underpinned the core curriculum and informed teaching. This has generated an extensive research and publications program, including supervision of doctoral students, some of whom may develop as future teachers of ANZSOG programs. This was followed by a series of other governmentsponsored senior academic research posts in other member jurisdictions, as well as joint teaching-research appointments. ANZSOG has also invested heavily in the development of 'teaching cases' aimed at executive education, with an available library now of more than 200 written case studies; these are all available to member governments and university partners at no cost.

While ANZSOG naturally shares many characteristics with other 'schools of government', it also has several distinctive features. These can be summarised as follows:

- ANZSOG is a not-for-profit consortium of stakeholder governments and universities designed to achieve economies of scale and scope in addressing the needs of government.

- It is a collaborative partnership between two nations (Australia and New Zealand).

- Governments identify and nominate emerging leaders from around Australia and New Zealand, and support them financially during their engagement with ANZSOG.

- The school has the capacity to attract first class teachers from Australia, New Zealand and overseas.

- Its rigorous EMPA is accredited by Australian and New Zealand universities.

- The school offers a research-driven, practitioner-oriented curriculum.

- Its pedagogic philosophy stresses innovative and engaging program delivery.

- It has managed around 20 major international conferences on topics of direct interest to practitioners and many workships and seminars.

- It has strategic linkages with other prestigious international schools of government in Europe, America and Asia. 
Six significant factors have contributed to ANZSOG's institutional progress and the continuing high level of support it enjoys from both its government members and university partners. First, the school has prioritised a continuing focus on meeting governments' needs in senior executive development, with the corollary that continuing support from government stakeholders has required maintaining relevance and high levels of customer satisfaction. Second, it has invested in, and provided dedicated educational programs to, its stakeholder governments. Third, it has demonstrated a commitment to teacher development focused on effective postgraduate/mid-career teaching and learning. Fourth, it has actively utilised an extensive network of scholars and practitioners, across Australia and New Zealand and internationally, to provide input into programs and courses. Fifth, the school has maintained an active engagement with, and support from, alumni, including providing ongoing educational refreshers and network opportunities. Finally, the school has operated within a robust business model designed to maximise its effectiveness and influence, while providing value for money for governments and participants.

\section{ANZSOG's distinctive participant population and teaching innovations}

Participants in ANZSOG's executive development programs were generally middle to senior officials with significant experience and embedded practice backgrounds. They were highly engaged, motivated and possessed a high performance culture in the commitment they put into the learning environment. They were energised through reflecting on a range of theoretical insights and explanations of best practice presented to ensure they were serving the demands of government and the needs of the community. These features placed unique demands on the teaching and learning process. Teaching was not simply a matter of delivering content in traditional lecturing modes. Learning had to take place in a realistic and dynamic environment, pitched at the right level to connect with participant experiences and capabilities, and developed with tangible takeaway messages that deliver benefit to the participants in their practice environment. 
ANZSOG has developed over time its distinctive learning-centred pedagogical approach to respond to the opportunities presented by this challenging cohort and the important roles they already play in promoting good public policy outcomes and good public management practices. ANZSOG has worked collaboratively with the Kennedy School of Government at Harvard University to develop a practically oriented structure of developmental learning that builds on a core set of foundations, namely delivering public value, managing organisations, governing in a market economy, designing programs, decision-making under uncertainty, governing by well-designed rules and regulations and leading public sector change. Initially, in the masters program, the school promoted the interactive 'teaching case' pedagogical approach, but over time it developed in tandem with innovations in pedagogy drawing on interactive learning. The aim of interactive education was to broaden and diversify the learning experience through deploying a range of 'teaching methods' or sources of information. 'Teaching cases' became complementary to a range of other available teaching approaches including guest expert presenters and greater use of digital-based learning to promote active applied learning by all participants in the learning environment (see Alford \& Brock 2014).

Another innovation ANZSOG has developed has been the immersive case' as a pedagogic experience to stretch participant learnings. Immersive cases are 'live issues' that demand policy attention and involve participants (instructors and learners) performing site visits and working 'in the field' with policy or management issues in a real world context, especially nominated by owner governments of ANZSOG who might be grappling with a particular matter at a point in time, and are seeking the 'wisdom of the crowd' from participants in how to address intractable challenges or 'wicked' issues. For example, the TSL program divided participants into groups to address the particular challenges of dealing with homelessness in Victoria. This pedagogy was also employed on an inter-jurisdictional level to expand comparative learnings across Australia and New Zealand. It is now a crucial component of ANZSOG's international collaboration, with program participants in the EMPA and EFP travelling to Singapore and investigating 'live thematic issues' pertinent to Singaporean society, and working on presentations to project sponsors attached to the 'live policy challenges'. EFP participants have also been engaged in immersive case experiences in New Zealand concerning the film industry, with students 
matched with project sponsors, subject matter experts, instructional coaches and live site visits. A variety of practical proposals were generated that were communicated back to industry and government sponsors.

ANZSOG's work-based project in the EMPA serves as the capstone collaborative project with research topics nominated by agencies within member governments. Groups of five to six participants investigate policy problems or topics, frame their analysis and methodologies, and report their findings in oral presentations and written reports, often in seminars back to the nominating agency. While research-based projects have been employed in courses in other universities, ANZSOG began systematically to mine the topics and information gathered to inform the school about the main issues of concern to governments and extract policy learnings across time and across the federation and Trans-Tasman setting.

Under a new dean, ANZSOG refreshed its teaching and learning strategy in 2018-19 as part of its new ANZSOG 2025 strategy review, which was initially approved by the board in late 2018 with the implementation plan approved in May 2019. An additional investment of resources up to $\$ 9$ million was committed to the strategy over three years. The strategy called for greater stakeholder engagement, new marketing channels, revised curriculum and course offerings, more immersive experiences and 'adaptive offerings', greater use of innovative digital and online platforms in 'blended delivery' modes, customised support for instructors and institutional accreditation for tertiary-level courses. A key aim was to make learning increasingly active, curated and personalised. It also prioritised a greater focus on inclusion and diversity, including developing Indigenous peoples in the school's programs and incorporating Indigenous perspectives and cultures across the education programs.

Together, the distinctive participant populations and the pedagogic initiatives undertaken by ANZSOG were aimed at injecting direct value to actual public policymaking as well as better public management practices across the region. Internal ANZSOG research on the school's alumni suggested that participants found great value in the school's programs, and regularly rated their educational experience highly, averaging 4.2 out of 5 between 2012 and 2016 cohorts (ANZSOG 2019). Many frequently cited important aspects of learning that they operationalised at their places of work (such as the strategic triangle concept, adaptive leadership, the authorising environment, responsive regulation and collaborative leadership). Participants also greatly appreciated a number 
of by-product benefits associated with ANZSOG's cross-jurisdictional educational structure, including building networks and developing expert communities of practice. Alumni reported that they were better able to work within complex organisations, frame and interrogate problems, converse with colleagues, demonstrate self-awareness, use contacts and inter-jurisdictional networks, and promote collegiality and public sector camaraderie. In short, respondents have deepened their expertise and knowledge as well as enhanced their inspirational commitment to what the present board chair has called the 'spirit of service' (Hughes 2018).

\section{Dilemmas and challenges in delivering high-quality executive development programs}

The discussion that follows draws on extensive experience from academics working closely with senior public servants and government employees in educational environments. It is evident that, for many public sector executives, executive education opens new horizons, provides new knowledges and understandings, provides windows into alternative ways of thinking, and challenges them to translate theories and models into applicable learnings. It is often the case that inspirational presenters can transform the learning environment in class and leave lasting impressions on participants. Applied adult education can unleash the potentiality of higher learning in those with ample experience of work and professional development. In particular, schools like ANZSOG help program participants to transition from backgrounds in technical knowledge into public policy and policymaking, and provide an awareness of the imperatives of political governance, including developing a stronger sense of professional coherence. However, there are some very real challenges in directing education to these senior career public officials, not all of which are unique to the ANZSOG participants. First, government executives, especially those with more seniority and responsibilities, are a very particular type of course participant. Many undertaking executive development opportunities think they 'know it already'; they believe they cannot be taught much from formal programs and/or that academics cannot 'teach' them anything of importance. Many are not as curiositydriven as they could be but instead view executive education as a way of gaining formal competencies, accumulating frameworks to deploy 
as modus operandi and investing in networking. Recipients as well as presenters often prefer the intensive or concentrated mode of learning, where they are corralled into training courses for about a week (three to six days) often with a residential component, or for repeated intensive days some weeks apart. Intensive modes can assist new learnings to resonate and readily be built upon in subsequent classes; however, they also allow relatively little time for wider contemplation, genuine reflection, wider reading, written assignments or demonstrated comprehension. Classbased delivery in teaching venues (even when interactive participation is encouraged) is typically an unreal environment in which busy executives have taken time out to contemplate and reflect on the curricula. Many participants are time-poor, and already have intensive work-life balance challenges in their lives. Reading time is often restricted, leading to cramming and skimming, and almost always limited to the readings provided by the course presenters. Most of all, many executives are not allowed to (or cannot) 'leave work' behind and are constantly focused on problems or crises at work, on their mobile phones or heading back to the office, all of which reduces their concentration levels and attention spans. Too many participants in executive programs have a 'completion' mentality and requirement for credentialism, gaining higher degree credits or maintaining attendance to gain proof of completion and perhaps certification.

Second, there is the issue of what course participants themselves bring to the educational programs. Many executives bring considerable practical experience to the classes, gained from years of professional engagement within the sector. Indeed, this factor may be precisely why they have been nominated by their agencies for further executive development. The experience, however, may be in relatively circumscribed niches, leaving them with relatively little broader policy or managerial expertise or abilities. Hence, there may be some caution warranted when considering someone's experience in senior management of say 15 years: it may span 15 complex years in many challenging environments or consist of one year 15 times over. Class participants tend to attract both sorts of experiences, which serves to complicate the learning environment.

There is also the issue within agencies of which age cohorts should be trained for maximum benefit. Twenty to 30 year olds generally do not have the required experience and are not usually in substantive positions to be able to use the imparted knowledge. Those in their late 30s and 40s are the primary target group for executive development, but may not be 
intending to remain in the public sector in five or 10 years. Those over 50 or approaching 60 may need and appreciate executive training but there is a declining marginal utility in the investment. So, how to identify the next generation of future leaders remains a major problem for elite executive schools of government, as it is for public service departments and agencies. Historically, many 'fast-tracking' or 'hot-housing' schemes have reported limited success, with those officials eventually reaching senior posts often not having been selected into the hot-housing programs. ${ }^{5}$ Occasionally, executive training may be regarded by agencies as a reward for past service, going to those who have 'earned' kudos or met targets, and not necessarily those most likely to succeed, innovate or lead the agency in the future. Having said that, it should be recognised that ANZSOG is perceived as a prized program and competition in jurisdictions for places is often intense.

Third, on the supply-side, instructors, many of whom are academic class teachers and guest presenters, may be less familiar with the world of the practitioner and not comprehend the pressures they may be under. Often academics have never worked in the administrative public sector or performed routine bureaucratic jobs. Many of the executives these instructors hope to motivate are ingrained with agency cultures and bureaucratic norms, accustomed to hierarchical decision-making practices, too harried to be reflective or to undertake the necessary research, working with difficult bosses, and often filling in for others who may be away from the job. Academics tend to draw from what they know best: bodies of literature, critiques and key debates, explanatory concepts or precepts, simplified modelling, familiar articles or current academic preoccupations. These are real bodies of knowledge to them and frame the way they see the world. Academics may be able to teach for the allotted time in class sessions, but not necessarily translate or tailor their material to highlight the applicability to practical situations. For instance, many representations of classical incrementalism present the main aspects of the theory, limitations of knowledge, limited sequential comparisons of action, 'muddling through' and trial and error tactics, and root and branch adaptations, but fail to concretise the heuristic modelling for

5 The classic example in Australia was the deputy secretary scheme (intended to develop promising deputies into the next generation of secretaries, then called permanent heads), which ran throughout the 1960-70s. However, when the succession planning scheme was reviewed, very few of the deputies had made it to the top, and those that had had typically not done the fast-tracking scheme. Interestingly, ANZSOG has established its own deputy leaders program in 2018 available to member governments. 
audiences. Practitioners often recognise the model, not as normative 'best practice' or an ideal way of doing policy, but as an academic descriptive version of what they often see at work: the messiness of decision-making, people making it up as they go along and reactions to expedient stimuli. Too often, the applicability of abstracted models often has to take place in the minds of the recipients. Guest presenters with practical experience can 'ground' the learning opportunities, but they are often restricted to their own personal experiences, which are typically anecdotal; consequently, they struggle to translate their observations to broader contexts.

Fourth, in pedagogic terms, instructors and participants can resemble strangers dancing with strangers or ships passing in the night that are unlikely to bump into one another, with academics more interested in theoretical debates (assumptions, approaches, worldviews or weltanschauung) and practitioners interested in how to get their jobs done. Academics tend to be focused on problems and critiques of performance, while practitioners tend to be interested in proposing solutions in relation to salient issues on the agenda. In formal programs, the expectations of teachers is that participants will absorb learnings, be able to apply models and theories and contextualise learnings, and respect the expertise of those with knowledge. The expectations of the learners are to be challenged, reassured and entertained; they expect to enjoy some 'time out' from work and clear their head space and, above all, that their instructors will respect practical experience. Participants often have difficulty, not with following a given presentation, but with relating what has been presented with other approaches or interpretations, or into other contexts. At worst, presentations from practitioners can descend into a series of 'war stories' related from the distant past, with no help provided to ground the learnings, put them into context or help participants apply the learning (where, when and how). Required course readings authored by academics can be less 'mind opening' and may soon become a chore for participants who may not know what 'learnings' to draw from them. The use of simplified theories, models or key concepts is often presented in the abstract, devoid of real context, meaning that these heuristic devices typically airbrush out the messiness and complexities of real-life engagement with public policy (e.g. 'bounded rationality', 'market failure', the 'authorising environment', the 'strategic triangle', 'policy stages' or 'policy cycles', 'punctuated incrementalism', 'multi-streams analysis' and 'program logics'). Simplified 
models become stylised heuristics, arguably misleading as much as they inform (e.g. the debate over the 'policy cycle' heuristic is far removed from the real world of practitioners [see Cairney 2015]).

Fifth, 'teaching cases' are specially designed as problem-oriented learning exchanges, using background readings that condense aspects of a particular incident, issue, scenario or controversy. They can be excellent forms of pedagogy and are a renowned format of applied learning (although they can be a 'high wire act' for presenters unsure of where they may go). The pedagogic philosophy behind 'teaching cases' is that the smartest person in the room is the room itself (i.e. liberating the collective knowledge and experiences of capable participants). Most 'teaching cases' are written in parts to narrate a particular problem though various stages (pretending it is a live scenario) to allow for compartmentalised class discussion of alternative ways of proceeding or explaining proposed actions. However, there can be problems associated with the over-reliance on 'teaching cases'. Cases typically date quickly, become mainly of historical interest and are highly contextual. Participants need certain bodies of content knowledge and context before they can analyse a given case appropriately. Often classes divide between those that are very familiar with the case information, and participants for whom it is a bewildering puzzle with incomprehensible aspects, a phenomena that policy expert Professor Patrick Weller once called 'pooled ignorance'. If an experienced instructor discovered a class full of participants who knew little about the topic, how could they expect them to make sense of the case? Many participants will typically make naive or simplistic suggestions, politically unfeasible options or venture implausible proposals that would not gain realistic support. To illustrate this point, a few years ago, a group of transport executives exploring a case about traffic congestion in metropolitan cities discussed options and reported that the best way forward was to introduce road pricing for entry into the CBD; when a media leak occurred, the then premier stated that it was the most preposterous proposal he had ever heard and that it would not be happening under his watch.

It takes great skill from presenters to bring out the complexity and ambiguity of teaching cases and allow participants to reflect on the learnings. 'Teaching cases', while drawn from real world experiences, are somewhat artificial in classroom contexts. They are predictably post-hoc rationalisations, with the authors having the luxury of being wise after the event. Many signpost dilemmas and pitfalls, highlight misjudgements 
or shortcomings, and include some form of 'narrative closure' making endings predictable and the pitfalls readily avoidable by class participants. Many cases present clear examples of policy failure or poor judgement and no one in a course discussion will admit that they would repeat the decisions to allow that unfortunate scenario to eventuate. With the benefit of hindsight, class participants, when asked to make comments or assessments of case scenarios, often say that 'they wouldn't have done that', which makes them more circumspect and erodes the learning experience. Indeed, the 'wisdom of hindsight syndrome' is a really difficult quality to dislodge. In addition, with 'teaching cases', there is rarely any truly right or wrong answers; any nominated course of action or suggested solutions could be right or wrong, better or worse, depending on the context, prevailing imperatives and implications. Negotiating how to proceed in teaching cases is usually more a question of appropriateness and prudence. Post course follow-ups and alumni master classes can be part of the learning journey, as offered regularly by ANZSOG, and these can provide valuable updates and refreshers to former participants who may have attempted to apply executive learnings in their places of work.

Sixth, role-playing scenarios provide a sense of drama and entertaining interludes; they are good ways to get participants talking and engaged. However, even when 'real-life' scenarios are re-created, they do not replicate a real world situation when reprised in the class context. Such role-playing exercises are one-off exercises in which no one is really responsible for what they say or do, there is no real hierarchy or power disparity, and no repeated occurrences as would occur in ministers' offices or bureaucracies. Many role-playing exercises see participants merely wanting to seal the case, complete the exercise or find narrative closure, and, in learning terms, there is often a danger that participants will interpret this to mean that one comment is as good as another. Other gaming exercises, such as brainstorming and thinking outside the box scenarios, may also not be realistic representations, as they tend to find participants who "know the patter' but do not consider the risks or alternative perspectives. It is hard to game a scenario when no one has skin in the game and no responsibility for any conclusion or consequence. ANZSOG's adoption of 'immersive cases' in real-life contexts (which are similar to UK executive development experiences) aims to make case work far more realistic and powerful in terms of learning. 
Seventh, there is a broader problem of whether the content of programs is 'fit for purpose' and germane. How do we know if the focus on leadership, for instance, is a priority for agencies or the profession of public administration and whether it will enhance the capabilities of officials? Are notions of 'market failure', 'competitive advantage' or 'rent-seeking behaviour' useful concepts for non-economist public servants doing graduate courses? Training programs designed for senior executives (both in the public and private sectors) can become fixated on particular conceptions (such as strategic leadership, corporate planning, change management or an emphasis on 'public value'). Many public policy schools have now endorsed a normative 'public value' approach to public management, advocating a malleable concept encouraging various experiments in bureaucratic interventionism often more suited to US-style policy entrepreneurialism. The danger here is that the endorsement of a particular normative concept risks creating disciples rather than critical thinkers or sceptics. Critics may argue that the adoption of a pedagogy about administrative experimentation and the advocacy of a licence to go 'value-adding' by policy entrepreneurs can take precedence over more 'hard-edged' managerial education, stakeholder management, quantitative skills, data analytics and interpretations, implementation and project management capabilities. Often, too much emphasis on policymaking can neglect an exploration of the art and craft of public administration.

Finally, in the wider domain of executive education, there is frequently an overuse of PowerPoint presentations, with information-laden slides listing notable points and providing visual hooks. PowerPoint is generally a passive form of pedagogic learning, with presentations delivered as authorial scripts, often with little time to digest or discuss the contentious points. It is a convenient but unsatisfactory way of delivering complex information, usually with no explanation as to why a presenter has chosen to select certain information and exclude other information or rival approaches. Often many of the crucial explanatory variables are hidden in the white spaces between the bullet points or linked (somewhat mystically) between slides in the presentation. Unless the presenter is very skilled at narrative and explanation, PowerPoint slides tend to recite canon not analysis. 


\section{Conclusions}

Delivering high-quality training and development to senior executives across the public sector from different jurisdictions, different agencies and at different stages of career progression has its challenges and rewards. The intensive mode of teaching, which is typically associated with senior practitioner executive development, suits their work-life balance and busy work schedules. Classes become 'semi-retreats' away from the workplace, providing relatively 'safe spaces' where executives can share experiences, learnings and indiscretions, and speak honestly while benefiting from the interactive exchanges of a cohort of relatively similar level executives. However, there are distinct challenges in taking the learnings and insights gained through such classes and translating them into real practice.

Forty years ago very little of this intensive block executive education was delivered in Australian tertiary institutions, with the exception of a handful of graduate schools and institutes of management experimenting with intensive MBA programs. Now it has become the norm. So, where to from here? We might wonder whether such forms of intensive executive training and development will still be around in the next 20 or 30 years? Will they have been displaced by other more customised, self-paced forms of interactive learning, perhaps delivered closer to the real work environment? Or will there be a much-welcomed metamorphosis in which greater immersive experiences are widely adopted, with greater buy-in from agencies and supervisors, greater evaluation of the impact of executive development, and revised and improved pedagogical approaches?

Executive development programs have to find better ways of blending traditional 'hard' managerial skills with 'soft' relational skills. Specialist providers such as ANZSOG have to constantly recalibrate their course content, preferred curricula and chosen pedagogies. They need to explicitly clarify and justify the intended impacts of their delivery modes and monitor the out-year effectiveness of whatever developmental programs are undertaken. They need to reframe their offerings regularly to maximise impact and value for money, especially for the sponsoring agencies and participants. There is a clear imperative to engage more fully with public executives about how best to extend their individual and collective capabilities. Above all, as 'suppliers', specialist providers must ensure that they satisfy demand and continue to meet or exceed member government expectations. 


\section{References}

Alford, J \& Brock, J 2014, 'Interactive education in public administration', Teaching Public Administration, vol. 32, no. 2, pp. 144-57, doi.org/10.1177/ 0144739413515491.

Allen, P \& Wanna, J 2016, 'Developing leadership and building capacity in the Australian public services for better governance', in A Podger \& J Wanna (eds), Sharpening the sword of state: Building executive capacities in the public service of the Asia-Pacific, ANU Press, Canberra, ACT, doi.org/10.22459/ SSS.11.2016.02.

Australia and New Zealand School of Government (ANZSOG) n.d. [c. 2003], The establishment of the school, ANZSOG, Melbourne, Vic.

Australia and New Zealand School of Government (ANZSOG) 2013, Annual report 2012, ANZSOG, Melbourne, Vic.

Australia and New Zealand School of Government (ANZSOG) 2016, Annual report 2015, ANZSOG, Melbourne, Vic.

Australia and New Zealand School of Government (ANZSOG) 2019, ANZSOG 2025 strategy review, ANZSOG, Melbourne, Vic.

Australian Public Service Commission (APSC) 2004, Integrated leadership capability framework, APSC, Canberra, ACT.

Australian Public Service Commission (APSC) 2014, The integrated leadership system, APSC, Canberra, ACT.

Boston, J \& Eichbaum, C 2014, 'New Zealand's neo-liberal reforms', Governance, vol. 27, no. 3, pp. 373-6, doi.org/10.1111/gove.12092.

Cairney, P 2015, 'How can policy theory have an impact on policymaking', Teaching Public Administration, vol. 33, no. 1, pp. 22-39, doi.org/10.1177/ 0144739414532284.

Davis, G \& Wanna, J 1997, 'Does the teaching of public administration have a future?', Australian Journal of Public Administration, vol. 65, no. 4, pp. 1-5, doi.org/10.1111/j.1467-8500.1997.tb02482.x.

Di Francesco, M 2015, 'Policy analysis instruction in Australia', in B Head \& K Crowley (eds), Policy analysis in Australia, Policy Press, Bristol, UK, doi.org/10.1332/policypress/9781447310273.003.0017.

Fels, A 2003, 'The Australian and New Zealand School of Government', Canberra Journal of Public Administration, no. 108, June, pp. 75-6. 
Hughes, P 2018, 'The spirit of service', ANZSOG Patterson Lecture, Melbourne, Vic.

Podger, A 2003, 'Trends in the Australian Public Service, 1953-2003', Canberra Bulletin of Public Administration, no. 109, September, pp. 14-18.

Public Service Commission (PSC) 1992, Accounting for your training dollar, PSC, Canberra, ACT.

Public Service \& Merit Protection Commission (PSMPC) 2001, Serving the nation: 100 years of public service, PSMPC, Canberra, ACT.

Tiernan, A 2011, 'Advising Australian federal governments: Assessing the capacity and role of the Public Service', Australian Journal of Public Administration, vol. 70, no. 4, pp. 335-46, doi.org/10.1111/j.1467-8500.2011.00742.x.

Tiernan, A 2015, 'Craft and capacity in the public service', Australian Journal of Public Administration, vol. 74, no. 1, pp. 53-62, doi.org/10.1111/14678500.12134 . 
This text is taken from Learning Policy, Doing Policy: Interactions Between Public Policy Theory, Practice and Teaching, edited by Trish Mercer, Russell Ayres, Brian Head and John Wanna, published 2021 by ANU Press, The Australian National University, Canberra, Australia.

doi.org/10.22459/LPDP.2021.04 